\title{
Ground base deformation by circular plate peculiarities
}

\author{
Mykola Zotsenko ${ }^{1, *}$, Yuriy Vynnykov ${ }^{1}$, Iryna Lartseva $^{1}$, and Svitlana Sivitska ${ }^{1}$ \\ ${ }^{1}$ Poltava National Technical Yuri Kondratyuk University, Pershotravnevyi Avenue, 24, Poltava, \\ 36011, Ukraine
}

\begin{abstract}
It is established that at the moment of the onset of the boundary equilibrium of the base under a central loaded plate, an elastic core is formed in the form of a cone, all particles move along with the plate progressively down. In this case, within the limits of the "area of influence" the boundary condition of the base is violated by protrusion or consolidation of soils. The volume of the "area of influence" is determined by the height of the elastic core, from which its diameter is calculated. Experiments using conical tips were made and the height of the elastic core was determined and the diameter of the "area of influence" was determined. For creation at penetration and probing friction of soil on a ground the conic tip is executed rough with cylindrical stages. Under the steps of the tip, formed areas of compacted soil, moving along with it, creating a so-called "ground shirt" in the form of a cone with a creature at an angle $\alpha$ to the vertical. The obtained data allowed specifying coefficients of bearing capacity of soils, which are used in construction norms.
\end{abstract}

\section{Introduction}

Modern methods of mathematical modeling of geotechnical processes [1] provide the model construction of the structure surrounding soil foundation interaction [2-6].

With the gradual loading of a rigid circular plate from the surface the deformation of its base includes three phases [7]:

1 - a compaction phase, during which the elastic core of compacted soil is formed;

2 - a local sliding phase, where with further increase in the load on outside the core shifts begin to develop changes that occur first in the individual points of the array, and the growth of tensions occupy a larger area;

3 - a phase of destruction, where zones of local shifts are gradually guided, creating so-called sliding surfaces, with the complete plate formation significantly precipitates when bulging the soil on the surface and in the sides. Under a central loaded circular plate, an elastic core is formed in the form of a cone, all particles, along with the plate, move progressively downward.

\footnotetext{
${ }^{*}$ Corresponding author: vynnykov@hotmail.com
} 


\section{Analysis of resent research and publications}

Theoretical and experimental studies have established that at the time of the onset of the basis limit state of the plate correspond to $[8,9]$ :

- in case of the flow is the general shift of the soil around the plate behind the surfaces of the slide;

- in the absence of flow is soil consolidation around the plate.

Immersion of the plate occurs due to the displacement of the soil in the zone of the least resistance. Such zones, depending on the relative penetration of the die and the density of the sand, may be zones above and below the stem of the plate.

According to tests [10] the interaction of soil zones shift with parallel immersion of plates is felt in much wider boundaries than is predicted by the theory [11, 12]. Therefore, the determination of the geometric boundaries of the soil flow zone by immersing a plate is especially important for constructing a design destruction soil model.

\section{Establishing the objective and tasks of the study}

As mentioned above, under a rigid circular plate in the soil, an elastic core is formed, which after further plate loading disperses and densifies the soil around. Thus, a protrusion zone forms soil compaction. The effort that is spent on the formation of the zone is the limiting load on the base.

In the classical solution of Professor Berezantsev V., which is used in building codes, an elastic cone with an angle at the apex of $90^{\circ}$ is taken. Professor Malyshev M. took an elastic cone with an angle at the top of $60^{\circ}$ [8].

Of course, the height of the hard core determines the size of the calculation model scheme for the base destruction under a circular plate and, accordingly, the marginal load magnitude on the plate. Consequently, determination of the actual size of this zone is the main task when compiling the calculation base destruction model scheme under a circular plate.

Therefore, the purpose of the work is to clarify the known solutions for determining the boundary load on the plate. To do this, it is necessary to determine experimentally the height of the elastic core, which is formed during the circular plate loading.

\section{The main part of the study}

Soils penetration and sounding are usually carried out by immersion in metal of conical polished tips of different sizes and opening angles $2 \alpha$. At penetration, the conical tip is immersed in the soil only at its height; with further immersion of sounding soils $[13,14]$.

In the process of penetration (sensing), the process of soil destruction is modeled in accordance with the theory of boundary equilibrium of a disperse medium [15]. As stated above, in accordance with this theory, the soil destroys the elastic core of the compacted soil, and the use of polished metal tips is a certain deviation from the usage theory.

To create cone-shaped tips of soil friction, they were made rough with cylindrical steps, as shown in Fig. 1 [16]. The rough tip consists of a cone and a shank. Cone, made with cylindrical steps, which have a correlation

$$
\delta / h_{c}=\operatorname{tg} \alpha / 2,
$$

where $\delta$ - ledge; $h_{c}$ - rise; $\alpha$ - angle between vertical and a cone generator.

Under the conical tip steps there are formed compacted soil area, which move along with the tip and form so-called "ground shirt" in the form of a cone with a creature at an angle $\alpha$ to the vertical. 
a)

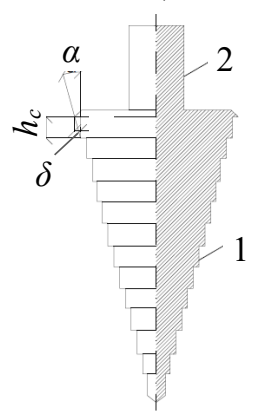

b)

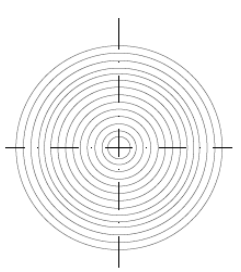

Fig. 1. Staggered tapered tip for penetration and sensing: $\mathrm{a}-$ section; $\mathrm{b}-$ plan;

1 - conical section; 2 - shank, $h_{c}$ - rise; $\delta$ - ledge; $\alpha$ - angle between vertical and a cone generator.

In Fig. 2, a the results of small-grained, quartz sand with a conical tip with an angle at the top tests $2 \alpha=30^{\circ}$ are given.
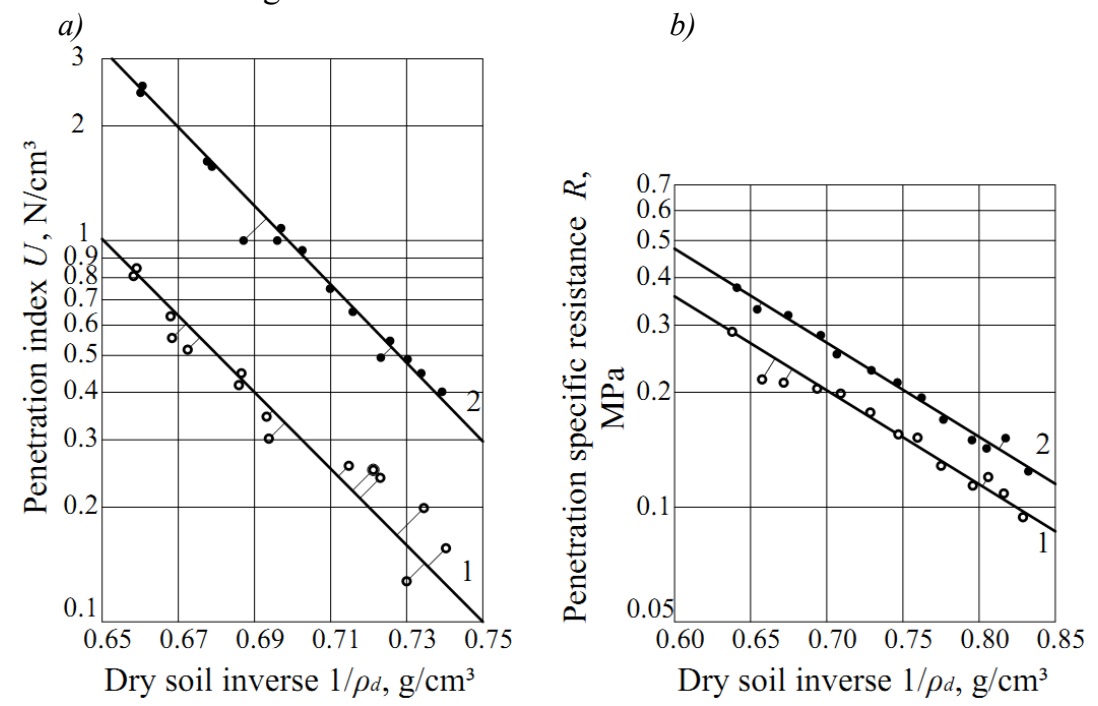

Fig. 2. Results of soils penetration tests with conical tips with an angle at the vertex $2 \alpha=30^{\circ}$ (with surface: 1 - smooth; 2 - rough: $a$ - sand; $b$ - loess soil.

The tests are performed using a laboratory penetrometer LP-1. Soil skeleton density varied within $\rho_{d}=1.37-1.52 \mathrm{~g} / \mathrm{cm}^{3}$. In this case, the angle of internal friction of sand fluctuated within $\varphi=32-36^{0}$. The averaging line 1 of the penetration index $U, \mathrm{~N} / \mathrm{cm}^{3}$, of the dry soil inverse $1 / \rho_{d}, \mathrm{~cm}^{3} / \mathrm{g}$, obtained using a tip with a smooth surface. The equation of this dependence is represented by formula (2) based on the results of 16 individual tests

$$
\lg U=5.329-7.058 \cdot 1 / \rho_{d}
$$

Equation correlation coefficient is $r=0.934$, and variation coefficient $v=0.195$, accordingly, straight line 2 is obtained using a rough tip on the results of 14 individual tests which indicates a close connection between research data and empirical dependence.

$$
\lg U=18.11-24.279 \cdot 1 / \rho_{d}
$$

The equation correlation coefficient is $r=0.946$ and variation coefficient $v=0.109$, 
which indicates the close connection between the experimental data and empirical dependence.

There is a significant difference in large sand penetration values. In the skeleton sand density range $\rho_{d}=1.37-1.52 \mathrm{~g} / \mathrm{cm}^{3}$ penetration index $U$, obtained by a rough tip, in 2.18 3.37 times higher.

In Fig. 2, b shows similar data obtained for the pulled loam of the broken structure. The angle of internal friction varied within $\varphi=14-16^{\circ}$, and the skeleton sand density $\rho_{d}=1.20$ $1.56 \mathrm{~g} / \mathrm{cm}^{3}$.

Straight line 1 dependence of the penetration specific resistance $R, \mathrm{MPa}$, on the inverse dry soil density $1 / \rho_{d}, \mathrm{~cm}^{3} / \mathrm{g}$, obtained using a tip with a smooth surface. The equation of this dependence is represented by formula (4) based on the results of 13 individual tests

$$
\lg R=0.721-0.732 \cdot 1 / \rho_{d}
$$

Equation correlation coefficient is $r=0.943$, and variation coefficient $v=0.136$, which indicates a close connection between research data and empirical dependence.

Straight line 2 dependences of the penetration specific resistance $R, \mathrm{MPa}$, on the inverse dry soil density value $1 / \rho_{d}, \mathrm{~cm}^{3} / \mathrm{g}$, obtained with a rough surface tip. This dependence is represented by formula (5) according to the 13 individual tests

$$
\lg R=1.003-1.036 \cdot 1 / \rho_{d}
$$

Equation correlation coefficient is $r=0.944$, and variation coefficient $v=0.122$, which indicates a close connection between research data and empirical dependence.

The pattern established for the sand remains, but the difference between the data obtained by tips with a smooth surface and rough, is much smaller.

According to the study [17], the friction angle of the soil beyond the surface of a smooth metal tip does not exceed $10^{\circ}$, which corresponds to the coefficient of friction $f=0.177$.

With the same surface area of the tips, the difference in penetration indicators values corresponds to the tangents ratio to the friction angles. For the sand $\operatorname{tg} 34^{\circ} / \operatorname{tg} 10^{\circ}=$ $=0.67 / 0.177=3.8$, and for the pulled loam of the broken structure $\operatorname{tg} 15^{\circ} / \operatorname{tg} 10^{\circ}=$ $=0.268 / 0.177=1.514$. The results of the calculations are close enough to the experiment.

A series of experiments was conducted to verify the impact of the angle at the apex of the conical tips $2 \alpha$ on the friction value of their surface during the static probing in a laboratory environment. The tests were carried out using a laboratory probing device LZU-1 of PoltNTU design. As soil, sand, quartz, large, slightly wet, which, at different density values, was placed in a tray with a cross section of $100 \times 100 \mathrm{~cm}$ and a height of $70 \mathrm{~cm}$. Conical metal tips with angles at the top $2 \alpha=20,30,45,60,90^{\circ}$ were made for sensing. For each of the angles there were produced tips with smooth and rough surfaces which are cylindrical stages. The diameter of the all the tips base was equal to $50 \mathrm{~mm}$. additionally a flat plate of the same diameter was made.

For each of the tips, sensing was carried out under seven indicators of dry soil. Further sensing with flat plate was conducted. The value of a sensing index $V, \mathrm{~N} / \mathrm{cm}^{3}$ was agreed on as probing characteristic, defined according to formula

$$
V=\left(P-P_{0}\right) /(H \cdot A),
$$

where $P$ - sensing force, $P_{0}$ - penetration force; $H$ - sensing depth; $A$ - base of the cone (plate).

In total there were 77 sensing tests performed, with sensing indices $V$ defined for them. Generalization of sensing results of sand of quartz, large, slightly wet, of different density with stage and smooth conical tips with different angles $2 \alpha$ are given in Fig. 3. 
a)

b)

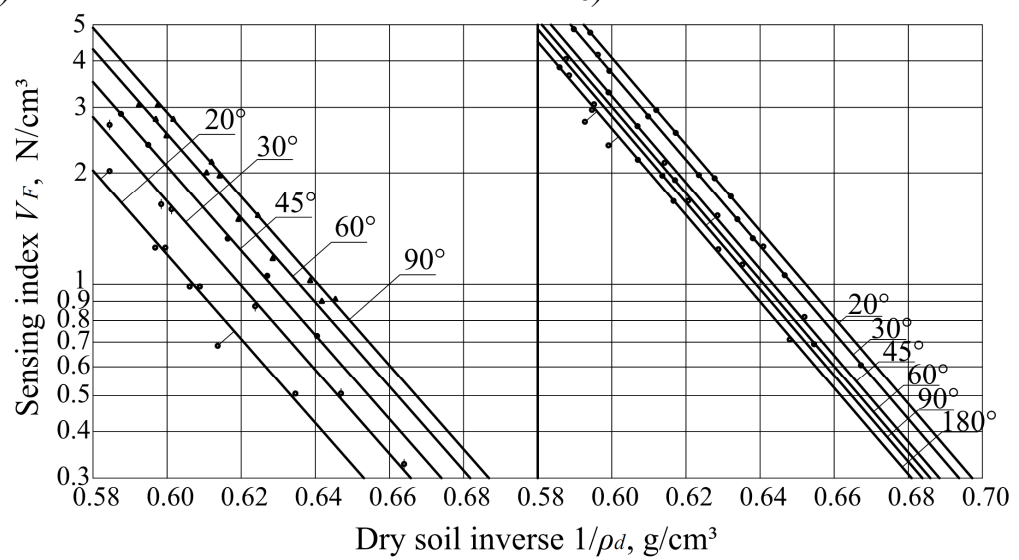

Fig. 3. Results of sensing tests of soils with conical tips with different angles at the vertex: $a-$ with a smooth outer surface; $b$ - with rough outer surface (stage).

For tips with a smooth surface received $A_{0}=15.738 ; A_{2}=0.0398 ; A_{3}=-9.753 ; \alpha_{0}=1$; $\rho_{d 0}=1$. Coefficient of correlation of the equation is $r=0.997$, and Fisher's test $F=178.35$.

For tips with rough surface received $A_{0}=-3.573 ; A_{2}=0.03 ; A_{3}=-2.753 ; \alpha_{0}=1 ; \rho_{d 0}=1$. The equation correlation index makes $r=0.993$, and Fisher criterion makes $F=75.29$.

While sensing sand with smooth external surface tips, the least sensing index was obtained for cone with $2 \alpha=20^{\circ}$ angle and the biggest for cone with $2 \alpha=90^{\circ}$ angle. This testifies that along the whole height of the elastic core there is friction of the polished metal with large sand that means observing the lowest coefficient of friction of the cone with the soil. For a cone with $2 \alpha=20^{\circ}$, area of the metal polished surface within elastic core is the smallest. That is why the biggest resistance is observed. It means that the height of the elastic core is less than that of the cone $2 \alpha=20^{\circ}$ and larger than the cone $2 \alpha=90^{\circ}$.

When sensing sand with rough cones and a stamp of friction within the height of an elastic core, only the soil was ground. Therefore, the least resistance to sensing demonstrate a stamp and a cone with an angle of $2 \alpha=90^{\circ}$. At smaller angles $2 \alpha$ we have an artificially enlarged elastic core and, correspondingly, a larger surface of soil friction on the ground.

To determine the height of elastic core, an experiment was conducted, based on sandy soils probing with halves of rough metal cones with different angles at $2 \alpha$ vertex, diameter of which is equal to the diameter of the plate. The immersion in such cones was carried out along a transparent screen that limited the sandbox. The sand in the tray was put in layers of a given density, which in height were separated by indicative layers of ground chalk.

When immersing the halves of the cones along the transparent screen, the soil near the plate deforms. This phenomenon was recorded by certain distortions of the indicative layers in the thickness of the sand. In Fig. 4 photos of submerged halves of rough (stepped) cones in large sand with indicative layers are shown. The experience of tray experiments $[10,12]$ shows that interaction of zones of influence altogether with parallel immersion of stamps is observed in broader boundaries than in theory. Therefore, determining the boundaries of the zone of influence on the surrounding soil while immersing plates, is especially important for constructing a calculation scheme of the soil destruction model. Under the "zone of influence" we mean the area of the soil base around the plate, within which it is possible to fix the stress from the load of the plate. Typically, the problem of fixing stresses in soils is solved by installing different types of pressure sensors (string, strain gauge, hydraulic, electromagnetic). These works require high costs and special equipment for performing them. However, such experiments do not always produce unambiguous results. The results of these tests are significantly influenced by the sensors contact conditions of the soil. 

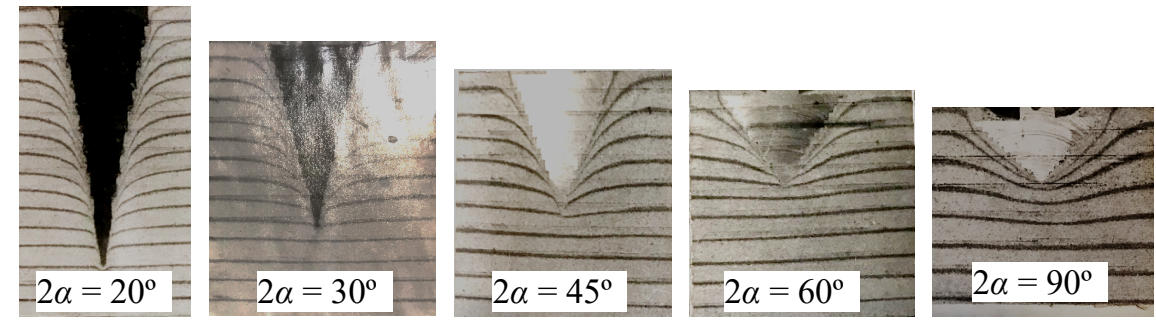

Fig. 4. Photo of the rough halves (stage) cones with angles $2 \alpha$, what are immersed in coarse sand.

We used a direct way to determine the zone of stresses distribution on the base model with conical foundation. It is based on the effect of a ring walls influence with a soil sample while conducting penetration tests. The effect is that under immersion of a conical tip with diameter $\mathrm{d}$ and angle of opening $2 \alpha=30^{\circ}$ in the soil placed in a metal ring at the certain depth of immersion of the tip (the critical depth of immersion $h_{k}$ ) there is a violation of invariance of specific penetration resistance, $R$, for clay soils, or Penetrance, $U$, for sands. This effect definitely determines the achievement of the "zone of influence" boundary the tip of the ring walls. The method of a sample preparation in advance guaranteed perfect homogeneity of the soil in the ring for each of clay and sandy soils sample in the given density ranges.

Examples of such violation of the penetration indicator invariance are given in Fig. 5. Here should be noted the high sensitivity of the method to the slightest violations of the conditions of experiment conducting, which in turn testifies of its sufficient accuracy. According to the graphs in Fig. 5 a similar violation of the invariance of the penetration specific resistance (penetration indicator) is characterized by a marked deviation of experimental points to the right of the averaged line.

a)

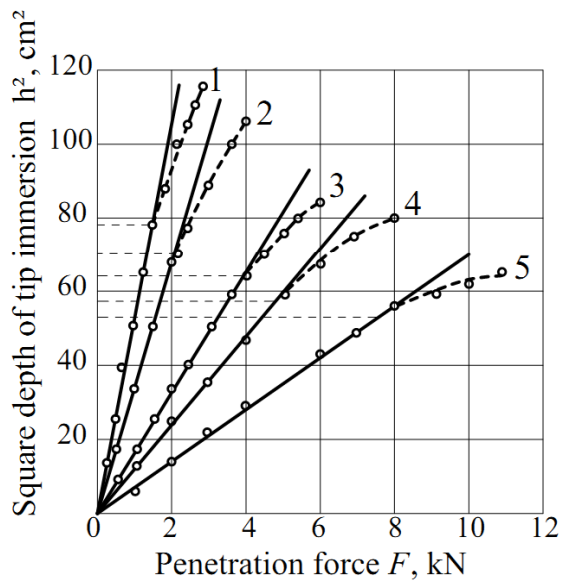

b)

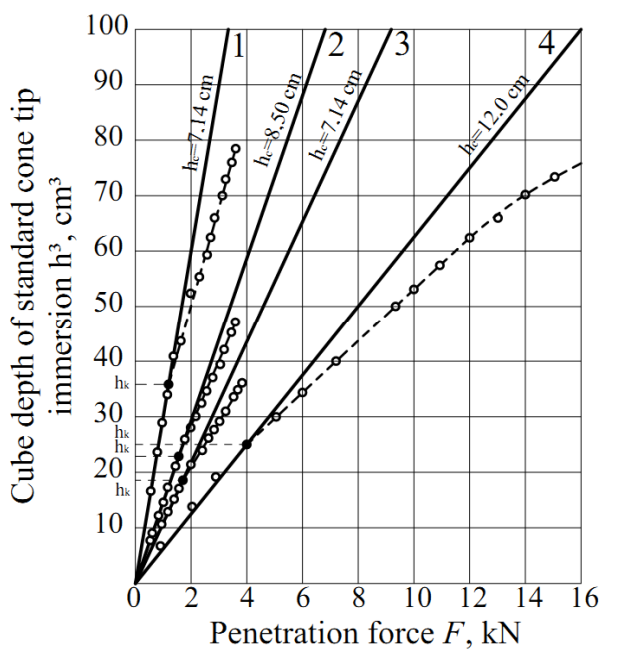

Fig. 5. Graphs of soil penetration with a conical tip: $a$ - loams and sandy loam in the range of the angle of internal friction $\varphi=12-26^{\circ} ; b$ - quartz sand, shallow, air-dried in the range of $\varphi=22-38^{\circ}$.

Thus, for each penetration test of clay and sandy soils of different densities and correspondingly, the angle $\varphi$, the diameter of the "zone of influence" $D_{i}$ is determined by the critical depth of the conical tip $h_{k}$ immersion. In Fig. 6, curve 1 corresponds to the results of clay and sandy soils sensing in the range of the angle $\varphi=12-38^{\circ}$. Each point on the graph is set according to the results of five parallel tests. The equation of the curve, established by correlation analysis, has the following form (at $r=0.996$ and $v=0.048$ ) 


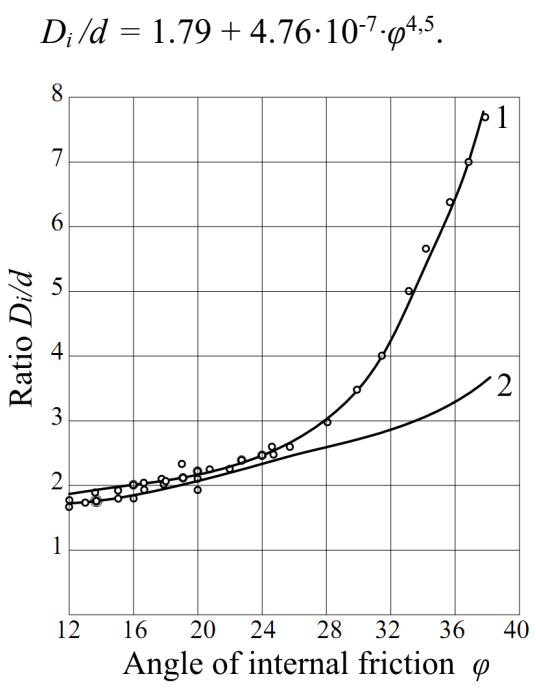

Fig. 6. Curves for determination of diameters 1 - "zone of influence" and 2 - "zone of compaction", depending on the angle of soil internal friction $\varphi$ and diameter of plate $d_{p}$.

For comparison in Fig. 6 shows curve 2, which is set for the pyramidal piles based on the results of field tests of the diameter of the "zone of compaction" of soil $D_{c}$ by methods of penetration and sensing. The corresponding equation has the form

$$
D_{c} / d_{p}=1.39+\exp (0,024 \cdot \varphi),
$$

where $d_{p}$-diameter of pile; at $r=0.99$ and $v=0.024$.

Stipulates have shown that for clay soils with an angle $\varphi \leq 24^{0}$ the dimensions of the "zone of influence" practically coincide with the limits of the "zone of compaction". But for sandy soils at $\varphi>24^{0}$, the "zone of influence" in size exceeds the "zone of compaction". This difference is the more, the more the density of the sand, that is, $\varphi$.

\section{Conclusions}

Thus, on the basis of the conducted researches, a method for compilation of the calculation scheme of a solid model for modelling the soil destruction process with axial-symmetric loading of a flat plate is developed (Fig. 7).

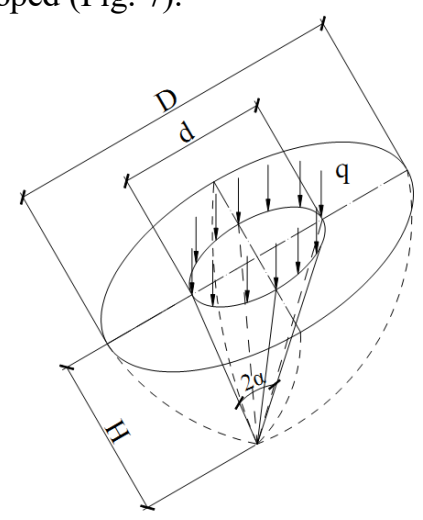

Fig. 7. Schematic diagram of the spatial model for mathematical modelling of the soil destruction process with axially loaded flat plate. 
On the surface of the half-space (the surface of the soil) we apply the area of the plate. Displays the elastic core in the form of a cone with the area of the plate in the base and the angle of opening $2 \alpha=44^{\circ}$. The diameter of the "zone of influence" (the distribution of stresses on the soil foundation) is determined by the graph of Fig. 6 by the magnitude of the angle of the soil internal friction. At a certain diameter of the "zone of influence" we take a circle on the surface of the half-space. The surface of the "zone of influence" is constructed by connecting a circle line with the top of an elastic core. To simulate the process at a certain depth of the base, we place the half-space surface evenly distributed load from the weight of the soil layer in a height equal to the depth of the plate immersion.

\section{References}

1. K. Chau, Numerical Methods, Proc. of the $18^{\text {th }}$ Intern. Conf. on Soil Mechanics and Geotechnical Engineering, Paris (2013).

2. M. Kelm, J. Grabe, FE-simulation of soil compaction, Proc. XIII ${ }^{\text {th }}$ European Conf. on Soil Mechanics and Geotechnical Engineering, Prague, 1 (2003).

3. N. Zotsenko, Y. Vynnykov, Designing the compacted subsoil's using mathematical simulation method, Active Geotechnical Design in Infrastructure Development, Proc. of XIII ${ }^{\text {th }}$ Danube-European Conf. on Geotechnical Engineering, Ljubljana, 2 (2006).

4. S. Henke, J. Grabe, Numerical modeling of pile installation, Proc. of the 17th Intern. Conf. on Soil Mechanics and Geotechnical Engineering, Amsterdam: IOS Press (2009).

5. K. Edip, M. Garevski, V. Sheshov, J. Bojadjeva, Numerical simulation of consolidation problem, Proc. of the XVI ECSMGE Geotechnical Engineering for Infrastructure and Development, Edinburg (2015).

6. P. Kryvosheiev, G. Farenyuk, V. Tytarenko, I. Boyko, M. Kornienko, M. Zotsenko, Yu. Vynnykov, V. Siedin, V. Shokarev, Innovative projects in difficult soil conditions using artificial foundation and base, arranged without soil excavation, Proc. of the $19^{\text {th }}$ Intern. Conf. on Soil Mechanics and Geotechnical Engineering, Seoul (2017).

7. A. Manjriker, I. Gunarante, Foundation Engineering, New York: Taylor and Francis (2006).

8. V. Berezancev, Raschet osnovanij sooruzhenij, Leningrad (1970).

9. M. Malyshev, Prochnost' gruntov i ustojchivost' osnovanij sooruzhenij, Moskva (1994).

10. V. Rasorenov, Penetracionnye ispytaniya gruntov, Moskva (1980).

11. E. Schultze, K. Melzer, The Determination of the Density and the Modulus Compressibility of Noun-cohesive Soils by Soundings, Proc. of the VI Intern.Conf. on Soil Mechanics and Foundation Engineering, Montreal, vol. I (1966).

12. M. Iskander, R. Bathurst, M. Omidvar, Past, present, and future of transparent soils, Geotechnical Testing Journal, 38 (5), (2015).

13. M. Omidvar, M. Iskander, Modeling of projectile penetration using transparent soils, Proc. of the $19^{\text {th }}$ Intern. Conf. on Soil Mechanics and Geotechnical Engineering, Seoul (2017).

14. H. Sturm, The tip resistance in layered soils during static penetration, Proc. of the $1^{\text {8th }}$ Intern. Conf. on Soil Mechanics and Geotechnical Engineering, Paris (2013).

15. M. Zotsenko, Y. Vynnykov, A. Yakovlev, Modern practice of determination of strength characteristics of cohesive soils by penetration methods, Proc. of XIV ${ }^{\text {th }}$ Danube European Conf. on Geotechnical Eng., Bratislava: University of Technology (2010).

16. Borvik Tore, Dey Sumita, L. Olovsson, Penetration of granular materials by smallarms bullets, Intern. Journal of Impact Engineering, 75 (2015).

17. N. Zotsenko, Y. Vynnykov, Rapid Investigation Methods of Soil Properties and Interpretation of their Results for Bridge Foundations Design, IABSE Colloquium reports on "Foundations for Major Bridges: Design and Construction", N. Delhi (1999). 